\title{
MEDIAÇÃO E A APLICAÇÃO DO CÓDIGO DE DEFESA DO CONSUMIDOR: PROPOSTA DE ESTUDO DO CASO MARIANA
}

\section{MEDIATION AND THE APPLICATION OF THE CONSUMER PROTECTION CODE: STUDY PROPOSAL OF MARIANA'S CASE}

\author{
${ }^{1}$ Lívia Carvalho da Silva Faneco \\ ${ }^{2}$ Larissa Barbosa Nicolosi Soares
}

\section{RESUMO}

O artigo problematiza o instituto da Mediação e sua aplicação para a composição de conflitos relacionados ao âmbito de aplicação do Código de Defesa do Consumidor e ainda de grande impacto social como o caso Mariana.

Palavras-chave: Mediação, Caso mariana, Direito do consumidor, Responsabilidade civil

\begin{abstract}
The article discusses the Institute of Mediation and its application to the resolution of disputes related to the scope of the Consumer Protection Code and of great social impact as the Mariana case.
\end{abstract}

Keywords: Mediation, Mariana case, Consumer law, Civil liability

\footnotetext{
${ }^{1}$ Mestre em Direito e Desenvolvimento pela Faculdade de Direito de Ribeirão Preto - FDRP, (Brasil). Colaboradoradora da Escola Superior de Direito - Ribeirão Preto - ESD, Brasil. E-mail: livia_carvalho_silva@ hotmail.com

${ }^{2}$ Mestranda em Direito pela Faculdade de Direito de Ribeirão Preto - FDRP/USP. Estágio Supervisonado pelo Tribunal de Justiça do Estado do Rio de Janeiro - TJ/RJ, Brasil. E-mail: larasoares87@ gmail.com
} 


\section{INTRODUÇÃO}

Recentemente o desastre ocorrido em Mariana/MG reintroduziu no meio jurídico a discussão a respeito da responsabilidade civil e ambiental dos causadores de desastres ecológicos. Entretanto, esse mesmo caso pode ser visto por outro ângulo, qual seja, o das vítimas humanas do evento em questão. Tratar dos direitos das vítimas de um desastre ambiental pode levar à adoção de diversas perspectivas, desde as de âmbito administrativista e de responsabilidade civil conforme o Código Civil, até mesmo na aplicação de métodos alternativos de composição de conflitos e a aplicação de diplomas normativos como o Código de Defesa do Consumidor.

Assim, dada a significância e abrangência de eventos e à magnitude do caso Mariana além da relevância social deste, o presente artigo optou pela análise dos direitos envolvidos em sede do CDC e os limites de eventual mediação, estabelecendo os critérios desejáveis para que esse instrumento seja utilizado de modo escorreito, sendo, portanto, eficaz na composição do conflito, sem deixar de garantir os direitos previstos pelo ordenamento jurídico às vítimas do evento danoso.

Desse modo, no artigo em questão será abordada a mediação como uma nova forma de pensar o direito e a possibilidade de aplicação da mediação para a composição de direitos decorrentes do Código de Defesa do Consumidor em caso de desastres ecológicos de grande porte ocasionados por uma concessionária de serviços públicos.

Portanto, a principal pergunta desse estudo é a seguinte: $O$ instituto da mediação pode ser utilizado para casos de eventos danosos em que seja aplicado o Código de Defesa do Consumidor? E caso seja possível, quais serão os limites apresentados?

A mediação é um instituto utilizado em grande monta para a composição de direitos disponíveis. Entretanto, direitos indisponíveis que admitem transação também podem ser objeto de mediação. Desse modo, em um primeiro momento, a aplicação da mediação a direitos concebidos no âmago do CDC seria possível, não apresentando qualquer vedação por parte desse diploma normativo em abstrato. No entanto, deve-se estabelecer se, tendo em vista a nova lei de mediação e o caso Mariana, ainda seria possível a utilização da mediação para compor conflitos de natureza consumerista em desastres de grande porte.

Assim, o objetivo principal desse artigo é demonstrar a possibilidade de mediação em eventos danosos para os quais o CDC é aplicável e estabelecer os limites que essa mediação deve apresentar quanto aos sujeitos envolvidos e ao objeto em discussão. 
Para isso, ter-se-á como escopo apontar o tratamento jurídico do instituto da mediação conforme a Lei 13.140/15 e também dos direitos do consumidor envolvidos a partir do estudo da relação jurídica de consumo e do consequente âmbito de aplicação do CDC. Com isso, discutir-se-á a possibilidade ou não da mediação ao caso concreto e avaliar-se-á os limites que essa possível mediação apresentaria nesse caso. Para tanto, utilizar-se-á de pesquisa teórico-doutrinária aliada ao método de caso com o método indutivo ${ }^{1}$, determinando em qual medida as determinações aplicadas ao caso Mariana poderiam se estender para outros desastres de grande monta.

\section{A MEDIAÇÃO COMO UMA NOVA FORMA DE PENSAR O DIREITO}

Com a recente publicação da Lei 13.140 de 2015, o marco jurídico que regulará a Mediação no Brasil, diversos estudos acadêmicos e doutrinas jurídicas ganham agora esforço legal não só para conceituar o instituto da Mediação como para materializar as boas práticas que vinham acontecendo pelo país ${ }^{2}$. A mediação, diferentemente da conciliação, possui ainda elementos que corroboram para uma nova forma de pensar o direito. A mediação não visa necessariamente ao acordo entre partes que estão em conflito - característica ímpar da conciliação - visa principalmente o reestabelecimento da comunicação ${ }^{3}$ entre partes que possuem uma relação continuada ${ }^{4}$ para que estas embutidas de poder por um mediador neutro assumam um protagonismo no processo não-adversarial na negociação de seus interesses (ALMEIDA, 2014).

Diversos estudos procuram definir a mediação de modos distintos, a saber, veem a mediação como um método, ou como um instrumento, ou como um conjunto de ferramentas, ou ainda como um saber prático, mas o que há de comum entre esses estudos é que a Mediação, aliada ao contexto da busca pelo Acesso à Justiça e suas implicações a partir da Constituição de 1988 e aliada ao novo marco regulatório que a Lei 13.140/2015 revela, traduz uma nova forma de pensar o Direito, o conflito e os agentes envolvidos em sua relação de

\footnotetext{
${ }^{1}$ Para Marconi e Lakatos (2007, p. 86): "Indução é um processo mental por intermédio do qual, partindo de dados particulares, suficientemente constatados, infere-se uma verdade geral ou universal, não contida nas partes examinadas. Portanto, o objetivo dos argumentos indutivos é levar a conclusões cujo conteúdo é muito mais amplo do que o das premissas nas quais se basearam".

${ }^{2}$ Para aprofundamento em algumas dessas boas práticas, ver: Grinover, Ada Pellegrini; SADEKE, Maria Tereza; WATANABE, Kazuo. Diálogos sobre Justiça: Estudo qualitativo sobre boas práticas em mediação no Brasil. Brasília: Ministério da Justiça, Secretaria de Reforma do Judiciário, 2014. Disponível em:

<https://direitosp.fgv.br/sites/direitosp.fgv.br/files/arquivos/anexos/relatorio_final_pesquisa_sobre_boas_praticas_de_mediacao_fgv_e_cebe pej.pdf> Acesso em 24.03.2016.

${ }^{3}$ Segundo Tânia Almeida (2014), as ferramentas para o reestabelecimento da comunicação são diversas, entre elas, podemos citar a escuta ativa, a legitimação dos sujeitos participantes, a validação dos sentimentos, a identificação dos impasses, a redefinição da fala com uma conotação mais positiva, transformação de relatos negativos ou acusações em preocupações entre outras.

4 "Sempre que a continuidade da relação é desejável ou necessária, as situações irão se beneficiar dos métodos ganha-ganha. Esses métodos são pautados no atendimento dos interesses e das necessidades de todos envolvidos na questão, de forma a propiciar satisfação e benefícios mútuos. Todos saem atendidos da mesa de negociações ganha-ganha, ao contrário dos métodos em que alguém sai ganhador e alguém sai perdedor, resultado mobilizador de raiva, sensação de fracasso e consequente sentimento de baixa-autoestima." (CUNHA, NORONHA, 2010, p. 51).
} 
cidadania. Focado na autonomia e independência das partes, a mediação transforma paulatinamente a visão do direito como um eliminador do conflito em uma visão do direito como um moderador e administrante do conflito através de suas próprias ferramentas e de propiciar um ambiente reeducador.

Nova forma de pensar o Direito, porque o instituto da Mediação já existia no Brasil há pelo menos dez anos, mas usado e conhecido como forma alternativa, tal como revelado pelo estudo Diálogos sobre Justiça, supracitado, e também como exceção à forma principal de solução de conflito, a saber, a via adversarial ${ }^{5}$ típica do processo judicial. Com o advento da nova Lei de mediação e também advento do Novo Código de Processo Civil - que via petição inicial exige a manifestação em relação à participação em sessão de mediação - o instituto passa a ser visto, ou desejado, como regra.

Ao institucionalizar as práticas de mediação através da instauração de Núcleos Permanentes de Solução de Conflito (NUPEMEC) contando ainda com toda a estrutura administrativa dos CEJUSCs (Centro Judiciário de Solução de Conflitos e Cidadania) vinculados ao Conselho Nacional de Justiça (CNJ) e os valores do Conselho Nacional de Instituições de Mediação e Arbitragem (CONIMA), tem-se o enforcement necessário para que a mediação seja essa verdadeira via de regra. O Poder Executivo também se mostra como forte contribuinte da mediação através de políticas públicas voltadas à justiça restaurativa ${ }^{6}$. Em cooperação com a justiça, os CEJUSCs: 1. proporcionam o ambiente para essa nova forma de pensar o Direito, incitando os profissionais do Direito bem como as partes cidadãs a serem pacificadores no lugar de litigantes, 2. viabilizam a aplicação desse instituto e, por fim, 3. promovem a reeducação dos cidadãos e a replicação das práticas pelos Municípios.

Faz-se necessária essa mudança no pensamento jurídico pois a ampliação do acesso à justiça, dada pela Constituição de 1988, elevou consideravelmente o número de processos judiciais tramitantes no país ${ }^{7}$. Se por um lado o aumento é salutar devido à democratização do acesso, por outro lado o Poder Judiciário se tornou a via preferida para solução de conflitos sociais que se repetem, ao mesmo tempo que a duração do processo não se torna razoável para

\footnotetext{
5 “O lugar da adversarialidade implica oposição, ver no outro um inimigo, um empecilho para seu desejo, a sua ideia, a sua proposta. É um lugar de afastado da curiosidade sobre o outro, afastado da reflexão, da possibilidade de incluir o discurso do outro, seu desejo, sua ação ou sua proposta como alternativas possíveis" (CUNHA, NORONHA,2010, p.39).

${ }^{6}$ Entende-se por Justiça restaurativa um conjunto de práticas de caráter não punitivo, assentado em valores, que tem como principal finalidade a reparação dos danos oriundos do delito causados às partes envolvidas - vítima, ofensor e comunidade - e, quando possível, a reconstrução das relações rompidas, no Brasil servem de apoio a Lei 12.594/2012, que regula as medidas socioeducativas, e principalmente o protocolo de cooperação interinstitucional para difusão da Justiça Restaurativa. (Disponível em <http://www.amb.com.br/jr/docs/protocolo.pdf > Acesso em 24.03.2016.

${ }^{7}$ Segundo dados de 2014 do relatório Justiça em Números, do CNJ, são quase 100.000 .000 de processos judiciais em andamento. Sendo o poder público o maior litigante do país (matéria tributária e previdenciária principalmente) e a justiça de primeira instância o maior número de processos tramitantes. Maior parte do total dos processos também está na esfera estadual (80\%). (Disponível em: <http://www.cnj.jus.br/programas-e-acoes/pj-justica-em-numeros> Acesso em 24.03.2016).
} 
uma prestação jurisdicional justa. Em outras palavras, o processo além de ser longo não garante a felicidade de uma das partes, em alguns casos, todas as partes estão insatisfeitas e desgastadas no final de um processo judicial litigioso.

O Poder Judiciário passou, ao resolver todo tipo de conflito que poderia ser evitado, a substituir o próprio poder advindo da cidadania dos membros da sociedade. Cidadania pressupõe a participação política não só através do voto, mas a participação nas decisões que interferem econômico, político e emocionalmente na vida de cidadãos, entregar ao juiz o lugar dessa decisão, sobretudo se elas puderem ser obtidas de forma não-adversarial, implica em renunciar ao caráter cidadão que existe em si mesmo.

A hipótese que contribui com o aparecimento da Lei de Mediação, nesse novo contexto, é o de que a maioria dos processos jurídicos poderiam ser evitados, ou poderiam ser resolvidos com maior protagonismo das partes, sendo elas mesmas ou outros integrantes, que não o juiz natural de Direito, melhores agentes para resolver o conflito. Através da mediação e da conciliação retiram-se inúmeros processos do Poder Judiciário. Enquanto uma nova forma de pensar o Direito, a mediação pressupõe que o conflito é "traço marcante e inerente à nossa condição humana e, mais ainda, um fenômeno social que pode emergir em diferentes planos individual, familiar, coletivo e estatal (...) é inevitável da interação com o outro” (ARAÚJO, FÜRST, 2014, p.354).

Tentar eliminá-lo demanda maiores dificuldades e gastos econômicos do que prever sua existência. Pelo menos, que o conflito não seja entregue primeiramente e rapidamente ao Poder Judiciário, terceirizando a cidadania. O que se percebe é que os conflitos entre partes que possuem uma relação continuada possuem em si grande potencialidade de se transformarem ao longo do tempo em novos conflitos, logo, ao não dissipar essa potencialidade, não se antecipam e resolvem esses novos conflitos resolvendo apenas um caso concreto.

A educação para a mediação viria então, além de substituir o juiz e evitar o número de processos judiciais - e os decorrentes problemas políticos, econômicos e de justiça - evitar-seia também a concentração e a potencialidade que um caso concreto em si carrega para se transformar em outro novo problema. Isso implica em devolver às partes a capacidade cidadã para resolver seus problemas e agir por si só na busca de seus interesses. Há na mediação necessariamente o empoderamento das partes devolvendo a elas a confiança que foi depositada em um determinado momento histórico ao Poder Judiciário. Em outras palavras, busca-se trocar a sensação final de um julgamento ganha-perde, ou perde-perde, para uma sensação final de uma mediação ganha-ganha. Não só o conflito tende a se resolver ali, mas a 
potência de um conflito se transformar em demais conflitos resta dissipada, antecipando assim uma nova atitude das partes que podem prever e antecipar através de uma negociação autônoma, sem a atenção futura do Poder Judiciário.

Os números de processos resolvidos e também evitados em matéria de direito de família consagrou a mediação como a solução adequada (e não mais "alternativa") enquanto meio de solução de conflito nas relações parentais, por sua taxa de sucesso ${ }^{8}$. A mediação foi largamente estendida às matérias de Direito Civil, Empresarial, Trabalhista e inclusive matérias do Juizado Especial Criminal (JECRIM). A Lei de Mediação prevê também em seu artigo $3^{\circ}$ matéria de direitos indisponíveis passíveis de transação, com homologação do juiz e oitiva do Ministério Público.

Casos em que envolvem a Administração Pública são comuns, já que esta é maior litigante do país e preocupa parte da doutrina a extensão relativa aos direitos indisponíveis. Mas é fato que a mediação na Administração Pública coaduna com os ideais de consensualismo que já permeavam a prática jurisdicional, através das inúmeras decisões reinterpretando a “indisponibilidade do interesse público". Decorrente da passagem do modelo burocrático de Estado para o modelo gerencial de Estado, essas decisões refletiam a dicotomia entre a Política e a Administração, onde a lógica desta última é reproduzir a centralização do poder nas relações e limitar o acesso dos cidadãos ao processo de decisão. Coaduna ainda com os princípios constantes do artigo 37 da Constituição, principalmente com o princípio de "eficiência" vez que a mediação evita a demora irrazoável do processo, princípios que também foram positivados no novo Código de Processo Civil de 2015.

O mediador é, pelas finalidades supra-apresentadas, um facilitador do diálogo ${ }^{9}$ que compreende que a justiça não se restringe à prestação jurisdicional, mas também ao esforço dos profissionais do Direito e das outras áreas na promoção da paz e prevenção do clima belicoso nas relações continuadas. O mediador é aquele que sabe separar as posições dos interesses ${ }^{10}$ das partes litigantes (ALMEIDA, 2014) e, através do mapeamento do conflito, eleva à consciência das partes o que há de comum nos posicionamentos complexos fruto daquela relação.

\footnotetext{
${ }^{8}$ Em alguns CEJUSCs quase $100 \%$ dos casos em direito de família são resolvidos, como de Caeiras onde a taxa é de $93 \%$. Disponível em: <http://caieiras.sp.gov.br/novo/centraldenoticias/?id=noticias\&Artigo_codigo=2739\#.VvSa0uIrLIU> Acesso em: 25.03.2016.

9 "Inspiradora de outros métodos dedicados ao diálogo inclusivo e participativo, como a Facilitação de Diálogos e o Diálogo Colaborativo, a Mediação oferece seus princípios, seus propósitos e seu instrumental técnico, construídos a partir do aporte de diferentes disciplinas, para a prática do diálogo produtivo - aquele que privilegia a escuta (e não a contra-argumentação), a construção de consenso (e não o debate), o entendimento (e não a disputa)" (CUNHA, NORONHA, 2010, p.36)

${ }^{10}$ Em uma sessão de mediação as partes apresentam a percepção que elas possuem de um conflito. Essa percepção configura a posição dela. O interesse é aquilo que o mediador através da escutativa percebe ser o desejo da parte exprimido na posição. O interesse é o que de fato importa para um bom mapeamento do conflito. Para aprofundamento, ler "Caixa de Ferramentas em Mediação" da Tânia Almeida (2014).
} 
Uma forma de superar o problema é trazer de volta o poder decisório para os agentes, cidadãos, através de uma gestão focalizada que enalteça a necessidade de cooperação - e não competição - entre os que são servidores para proteção do interesse público. Essa nova forma de olhar se conecta também com uma concepção de democracia participativa em contrapartida à democracia representativa ${ }^{11}$. Como de fato os assuntos em Administração Pública, como é o caso das concessões que o Poder Público faz para empresas privadas exercerem atividades econômicas, recaem sobre o interesse público e demandam uma participação cada vez mais integrada da sociedade com o Poder Público e com as empresas de grande porte, a mediação aparece como forma de integrar essas partes justamente quando há conflitos advindos dessa interação, por possibilitar condições de monitoramento.

Resta agora exemplificar como essa nova forma de pensar o Direito permite resolver de forma mais justa a integração dos interesses e solução de conflitos graves e de grande impacto social como é o caso Mariana.

\section{O CASO MARIANA: SEPARANDO OS INTERESSES DAS POSIÇÕES E COMPARANDO COM A MEDIAÇÃO DO PROGRAMA DE INDENIZAÇÃO DO VOO 447}

Em novembro de 2015 cedeu uma das barragens de rejeito da mineradora Samarco, conhecida como "Fundão" da unidade industrial de Germano, na cidade de Mariana em Minas Gerais. Em decorrência do acidente uma lama poluidora foi se esparramando por diversos distritos, como o de Bento Rodrigues ocasionando desabamento, demoronamento, poluição dos rios por diversas cidades até o mar do Estado do Espírito Santo. A empresa Samarco diretamente responsável pelas atividades de extração da mineração e que mantém empregados nas cidades afetadas é de capital fechado e é controlada 50\% pela Vale S.A e 50\% pela empresa anglo-australiana BHP Billiton Brasil Ltda.

$\mathrm{O}$ aspecto difuso dos direitos envolvidos, as indenizações devidas, o fato de o caso relacionar-se a uma concessão de serviço público para a Samarco realizar atividades de mineração, configuram soma de aspectos que interessam ao instituto da mediação, que foi o meio de solução do caso escolhido no que tange à responsabilidade civil pelos danos causados aos moradores próximos às barragens. Sendo esse um evento de grande impacto, e para esses eventos, como bem salientou Nadia de Araújo \& Olivia Fürst (2014), uma solução extra-

\footnotetext{
11 “A democracia meramente representativa, calcada em um modelo decisório basicamente agregacionista, voltado ao atendimento de posições jurídicas majoritárias, tem se mostrado incapaz de resolver o problema da intensa conflituosidade ambiental e da própria responsabilidade compartilhada entre Estado e sociedade civil. (...) o advento das - cada vez mais dinâmicas - relações globalizantes, propiciadoras do surgimento de corporações midiáticas agressivas, e os influxos do pensamento neoconstitucional, inseridos em um contexto de grave ativismo judiciário, implicaram em um acentuado ganho de poder desses setores com baixa representatividade política que passam a ter à disposição uma série de canais capazes de fazer pressão aos interesses da maioria" (MUNIZ et al, 2014, p.389).
} 
judicial customizada beneficia todas as partes envolvidas, vejamos agora os interesses que estão envolvidos no caso, para fins de uso da mediação como via adequada de solução do conflito e, deixando de lado os crimes ambientais causados e a responsabilização decorrentes - o que demandaria outro artigo - para medir apenas os interesses no que tange a possibilidade de aplicação do Código de Defesa do Consumidor ao caso em sede de responsabilidade civil.

É de interesse da parte causadora do dano ${ }^{12}$ a mediação para:

1. Melhorar a imagem da(s) empresa(s) que se encontra(m) afetada moralmente pelo desastre;

2. Evitar processo judicial litigioso que aponte uma indenização exorbitante aos consumidores;

3. Manter futuramente a concessão pelo Poder Público através de concessão.

Por outro lado, é de interesse dos moradores afetados pelo deslizamento:

1. Receber a indenização para mobilizar forças para reconstrução de suas casas e de sanar decorrente dano moral;

2. Receber a indenização para reinserção no mercado, caso haja prejuízo fruto do trabalho referente ao uso dos rios poluídos;

3. Evitar processo judicial litigioso que pressupõe possibilidades de recursos e demora da prestação jurisdicional;

4. Manter atividades das empresas, cujas atividades contribuem para sustento do trabalho.

Por fim, interessa também à Administração Pública, no caso o governo federal:

1. A solução do conflito;

2. A retomada das atividades não prejudiciais que contribuem com o mercado, com a economia nacional através, e somente nessa medida, do crescimento econômico sustentável ${ }^{13}$.

Interessa, por outro lado, ao Ministério Público:

1. Solução do conflito com indenização dos moradores, punição das empresas através de pagamento de multa (eventuais punições criminais serão excluídas por se tratar de direitos indisponíveis intransigíveis).

Essa soma de interesses é extraída de posicionamentos ${ }^{14}$ das partes que se estivessem em sessão de mediação seriam mapeados e monitorados ${ }^{15}$. Veja que um o Poder Público

\footnotetext{
${ }^{12}$ E aqui podemos ampliar como partes, para fins de estudo, a empresa Samarco, e também as empresas que através de seus acionistas controlam Samarco: Vale S/A e a BHP. Billiton Brasil Ltda.

${ }^{13} \mathrm{O}$ crescimento econômico sustentável é um crescimento que advém de atividades econômicas que contribuem ao produto interno bruto de um país, mas cujas externalidades negativas não inviabilizam as sociedades futuras de um ambiente saudável em sua totalidade. Trata-se de conceito largamente explorado após as influências das conferências em defesa do meio ambiente (Estocolmo, Kyoto, etc).
} 
possui portanto instituições dentro de si que podem inclusive divergir nos posicionamentos, em vista de suas finalidades institucionais.

O Ministério Público, de início, ao impetrar a Ação Civil Pública diante de suposta recusa da Samarco ${ }^{16}$ de assinar termo de compromisso, deseja conseguir para os moradores a indenização e um valor relativo ao dano causado bem como a suspensão das atividades violadoras do meio ambiente.

Já o Poder Executivo deseja que a indenização aconteça por meio de uma Fundação ${ }^{17}$ criada com as próprias empresas causadoras do problema. Isso porque interessa a eles a continuação futura das atividades após a responsabilização. Isso implica compreender que a mediação em matéria de direitos indisponíveis transigíveis que envolvam a Administração Pública assume finalidade de tornar questão complexa permeada por interesses dinâmicos em uma composição amistosa e includente. Se por um lado o governo conduz a uma mediação extra-judicial sem a participação de todas as partes envolvidas, incluindo as partes que parecem ser uma só, mas que se subdividem em posições e interesses diversos, perdem-se os elementos essenciais da mediação, tornando o instituto formal em uma prática vazia de sentido.

Isso porque não haverá elemento essencial: a voluntariedade das partes e ainda, diante dessa nova forma de pensar o Direito, não haverá o empoderamento das partes que a mediação provoca em entendimento com uma democracia participativa que recupera a cidadania dos cidadãos. A voluntariedade e a ampla participação garantem a mediação extra- judicial como uma medida justa e empoderadora. A falta de seus elementos além de provocar a via judicial como o lugar de decidir o Direito, voltando à tradicional prática, mantém uma potencialidade conflitual na sociedade, transformando o conflito nesse caso concreto no acirramento das posições conflitantes de instituições protetoras de interesse público com empresas privadas, governos e cidadãos.

\footnotetext{
${ }^{14}$ Os posicionamentos podem ser aferidos em grande mídia como Folha de São Paulo (Disponível em: <http://temas.folha.uol.com.br/ocaminho-da-lama/> Acesso em 24.03.2016) e entrevistas (Disponível em: <http://mariana1mes.brasildefato.com.br/> Acesso em 24.03.2016) e relatórios de Organizações Não Governamentais como Justiça Global (Disponível em: <https://issuu.com/justicaglobal/docs/vale_de_lama> Acesso em 24.03.2016) .

15 “O monitoramento - acompanhamento contínuo e sistemático por tempo determinado - é etapa imprescindível nas mediações com múltiplas partes, especialmente quando versam sobre questões coletivas. Nessas situações, o mediador (equipe de mediação) deve manter-se disponível para acompanhar a execução do acordado, para facilitar os diálogos entre representantes e representados e para coordenar as micronegociações que são naturalmente necessárias depois da construção do consenso" (ALMEIDA, 2014, p.190).

${ }_{16}$ Referido posicionamento pode ser encontrado em < http://agenciabrasil.ebc.com.br/geral/noticia/2015-12/ministerio-publico-entra-comacao-em-defesa-de-vitimas-de-tragedia-de-mariana> Acesso em 24.03.2016

17 Referido posicionamento pode ser encontrado em <http://agenciabrasil.ebc.com.br/geral/noticia/2016-01/governo-vai-criar-fundacaofinanciada-por-mineradoras-para-recuperar-rio-doce> Acesso em 24.03.2016
} 
Além disso, é fato que as empresas privadas detém hoje movimento de deslocalização e vantagem através de vantagem negocial decorrente dessa deslocalização ${ }^{18}$. Existe uma força que se traduz na forma de uma vantagem geograficamente reconhecida e institucionalizada entre aqueles que podem viabilizar grandes empreendimentos e que devem ser atraídos pelo governo para fornecerem empregos, atividades de fortalecimento estrutural e produtos exportáveis que neutralizam a força de participação dos cidadãos nas decisões do governo e ao mesmo tempo também neutraliza a força de representatividade dos movimentos sociais e de organizações não governamentais nesse poder de decisão.

Sobra ainda uma instituição pública que, se não está neutralizada por força de lei, acaba também sendo neutralizada pela demora do processo judicial, pelas discricionariedade e falta de previsibilidade de indenizações que, para além de favorecer os prejuízos individuais e coletivos, possa figurar como força de reverter a lógica dessa vantagem e possível manipulação das empresas privadas produzida pelo capitalismo internacional calcado na economia aberta.

O resultado é mais do que a flexibilização das regulações governamentais, mas uma substituição da capacidade política do Estado pelos grandes interesses econômicos não sustentáveis. O mercado estaria exercendo o papel de intermediar com ele mesmo - via estrutura estatal - os grandes conflitos sociais. Há nesse sentido um preenchimento de interesses específicos particulares no interesse público, ou o conhecido esvaziamento da esfera pública ou privatização do Estado. Não é de se espantar que eventos graves de degradações ambientais sejam predominantes em populações de baixa renda ou formada em grande parte por grupo étnico-raciais desfavorecidos historicamente, como índios e negros (ACSERALD, MELLO, BEZERRA, 2009).

O caso Mariana, ao demandar um programa de indenização para apaziguamento do conflito social, guarda semelhança com o desastre da Air France - vôo 447, em 2009. À época do acidente, foi criado um programa de indenização dos familiares do desastre baseado em solução extrajudicial com apoio de diversas instituições do Poder Público, empresas, e cidadãos envolvidos diretamente com o caso e seus representantes.

\footnotetext{
18 “As pressões dos portadores do poder de investir podem dar-se por dois meios: a) pela ameaça de retirada do investimento para outro local ou b) pela ameaça de que, não se aceitando o empreendimento tal como a empresa o deseja, nenhuma outra atividade análoga virá ali se implantar. Assim, um risco ambiental ampliado -incluindo também uma insegurança social no sentido largo, vide o exemplo do desmoronamento em 2013 de uma fábrica com milhares de trabalhadores precarizados em Bangladesh- é alocado sistematicamente às populações mais destituídas, por estas serem também, via de regra, deixadas ao largo pelos poderes públicos em termos de saúde e educação -com base na lógica da "livre-escolha" - 'infernal' - entre condições precárias e arriscadas de trabalho ou nenhum trabalho. A alocação concentrada sobre os mais pobres dos riscos associados ao empreendimento dar-se-á, assim, com frequência dramaticamente, tendo por base um certo grau de consentimento de populações expostas ao que chamamos de "chantagem de localização" (ACSERALD, 2008, p.110).
} 
O seu desenho de sistemas de resolução de disputas $^{19}$ contou, de acordo com Nádia de Araújo e Olivia Früst (2014), com os seguintes princípios: transparência - tomada de conhecimento de estatutos, propostas, parâmetros e critérios por parte dos familiares envolvidos e representantes;autonomia da vontade - tomada de decisão em participar é voluntária; isonomia - igualdade de tratamento e similaridade de casos para estipulação de valores; confidencialidade - compromisso firmado em termo e documentos trabalhados destruídos após fim do programa; eficiência - marcada pela celeridade e falta de burocracia; além da presença de autoridades públicas e apoio em critérios objetivos.

O programa de indenizações do vôo 447 contou, também de acordo com Nádia de Araújo e Olívia Früst (2014), com seguinte estrutura: Divisão de assistência - aporte com observadores de plantão para trabalhar na multiplicação do atendimento, preparação para ingresso das famílias no programa, suporte emocional garantindo neutralidade, mesmo trabalho que o observadores envolvidos com mediação realizam no estágio supervisionado para se tornar um mediador; Conselho consultivo e Conselho Diretor - órgão consultivo formados pelas autoridades públicas que deliberam sobre casos gerais, particulares e omissos e o último para pensar o programa;

Tal desenho parece servir ao olhar para o caso Mariana, se antes pudermos responder a seguinte pergunta: Trata-se de relação de consumo e portanto é aplicável o Direito do Consumidor ao caso Mariana para que o instituto da mediação seja inclusive comparável ao caso do voo 447 ?

\section{4 ÂMBITO DE APLICAÇÃO DO CDC, RELAÇÃO JURÍdICA DE CONSUMO E SERVIÇOS PÚBLICOS}

Falar em aplicação do Direito do Consumidor mais especificamente ou do Direito de per si a determinado fato social é, em primeira medida, destacar as relações de imputação de fatos a normas. No caso do Direito do Consumidor esse percurso lógico perpassaria a análise da relação jurídica de consumo e o âmbito de aplicação do Código de Defesa do Consumidor (CDC), culminando, neste estudo, com a aplicação ou não de suas normas ao caso de Mariana/MG.

Em primeiro lugar, falar do Direito como fenômeno social é instituir uma estrutura que, no caso de contingências, vale-se de expectativas normativas, isto é, expectativas cuja estabilidade se dá de modo contrafático, independente de se realizarem empiricamente ou não. (FERRAZ JR., 2007).

\footnotetext{
19 "altamente aprimorado e organizado conjunto de procedimentos, criados sob medida para lidar com situações específicas de amplo espectro" (MUNIZ et.al, 2014, p.355/356)
} 
Apesar do caráter contrafático da experiência jurídica, ela não se dá de modo apartado absolutamente das expectativas provenientes de atitudes cognitivas, ou seja, em casos extremos de falta de estabilidade de expectativas por meio das normas jurídicas ocasionaria o fenômeno da anomia, em que a norma jurídica, por não ser respeitada de forma alguma, é incapaz de estabilizar as expectativas de seu funcionamento (FERRAZ JR., 2007).

No entanto, em situações em que a função estabilizadora da norma está presente, fala-se na categoria da imputação. Imputar significa que dada uma situação determinada consequência a ela será imputada. Dentro dessa seara da dogmática analítica é que se estabelece a relação jurídica.

O tema da relação jurídica é de grande importância para a dogmática e em seu desenvolvimento histórico apresentou duas principais teorias:

1. a teoria normativista de Kelsen, que vê a relação jurídica como uma relação entre normas, ou seja, não reconhece autonomia para a relação factual em si, mas vê relação apenas como a disciplina em si, como o que Tércio Ferraz Jr. (2007, p. 166) entende como "sentido normativo da conduta". 20

Deve ser entendido, portanto, que a teoria normativista ao partir do pressuposto que determinada conduta humana, previamente prescrita pela ordem jurídica, seria a própria forma de constituição da relação jurídica, não haveria como separar a norma instituidora como apenas reguladora, sendo, desse modo, a relação jurídica uma relação entre as normas e não entre sujeitos. Caso não fosse assim, ao Direito de nada interessaria a análise da relação, uma vez que, se não tratar de normas, não está no âmbito de estudos da ciência do direito (Kelsen, 1991).

2. Em segundo lugar a teoria dos dois sujeitos estabelece que só as pessoas podem ser sujeitos da relação jurídica, não havendo, desse modo, relação jurídica sem os dois sujeitos constituintes. (REALE, 2002).

Os sujeitos da relação jurídica podem ser tanto indivíduos quanto indivíduos e o Estado. Nesse sentido, o Estado atua tanto como constituidor das normas, quanto como reconhecedor da validade das normas estabelecidas entre particulares (REALE, 2002). Essas diferentes relações podem ser chamadas de relação de subordinação e relação de coordenação, respectivamente (FERRAZ JR., 2007).

\footnotetext{
${ }^{20}$ Nesse sentido explica Kelsen que: "Então a relação jurídica estabelece-se entre a norma que obriga o comprador e a norma que obriga o vendedor, ou entre o comprador e o vendedor, melhor: entre a conduta de um, prescrita pela ordem jurídica, e a conduta, também prescrita pela ordem jurídica, do outro. (Kelsen, 1991, p. 180).
} 
Não se pode esquecer que a relação jurídica, independentemente da tese adotada, depende de uma estrutura normativa, ou seja, de um ordenamento jurídico base em que as condutas estejam previstas. Além do elemento essencial da estrutura normativa, a relação jurídica tem como elementos o sujeito ativo, passivo, o objeto e o vínculo de atributividade (REALE, 2002).

O sujeito ativo é aquele que é portador de um direito subjetivo, ocupando, assim, a situação jurídica ativa, sendo o credor da prestação principal, enquanto o sujeito passivo possui um dever jurídico e ocupa, desse modo, uma situação jurídica passiva, sendo o devedor da prestação principal. O objeto da relação jurídica, por sua vez, é um bem, podendo ser patrimonial ou não (NADER, 2008), sendo mesmo uma atividade da outra parte, mas nunca a pessoa em si (VENOSA, 2008). E por fim, o vínculo de atributividade é a relação, o liame que liga os sujeitos da relação jurídica, podendo ter por origem o negócio jurídico ou a lei (VENOSA, 2008).

Dentro da análise da relação jurídica a que interessa ao presente estudo, deve-se destacar os requisitos especiais de uma relação jurídica de consumo. Como qualquer outra relação jurídica, ela é composta por quatro elementos distintos: o sujeito ativo, o sujeito passivo, o objeto e o vínculo jurídico que os conecta. No caso dessa relação jurídica especial esses elementos podem ser traduzidos pelos conceitos de consumidor, de fornecedor, produto ou serviço, sendo o liame jurídico travado pelos institutos de Direito do Consumidor, respectivamente.

A importância da delimitação dos elementos de uma relação jurídica de consumo se coloca no sentido de estabelecer, a partir de então, qual o âmbito de abrangência do Código de Defesa do Consumidor. Para responder essa questão o próprio Código traz, parcialmente, as respostas, deixando ao intérprete a tarefa de delimitar a aplicação de suas normas por meio da interpretação de seus institutos. Apesar de ser tarefa altamente benéfica para a dogmática, a presença de interpretações muito divergentes pode se tornar problemática à asseguração de expectativas, em outros termos, à segurança jurídica (ZAPATER, 2001).

Devido ao limite que esse estudo apresenta, tratar-se-á apenas do conceito jurídico dos elementos da relação de consumo, abstendo-se do tratamento dos conceitos filosóficos, sociológicos ou econômicos, abordando-os apenas na medida em que interessam para a delimitação do conceito jurídico e aplicação e interpretação do Código de Defesa do Consumidor. $^{21}$

\footnotetext{
${ }^{21}$ Sobre os conceitos econômicos, filosóficos e sociológicos de consumidor vide: LuCCA, Newton de. Direito do Consumidor: Teoria Geral da Relação Jurídica de Consumo. 2.ed. São Paulo: Quartier Latin, 2008.
} 
O grande diferencial da relação jurídica de consumo é o chamado por Cláudia Lima Marques de "campo de aplicação subjetivo", uma vez que, caracteriza uma definição subjetiva relacional da relação jurídica de consumo, ou seja, em termos materiais, o CDC se aplica, a princípio, a qualquer relação contratual ou extracontratual, entretanto, seu âmbito de aplicação fica limitado, aplicando-se apenas quando a relação jurídica apresentar um consumidor e um fornecedor (BENJAMIN, MARQUES, BESSA, 2010).

O sujeito ativo da relação, ou o consumidor, é caracterizado pelo Código de Defesa do consumidor de duas diferentes formas: o consumidor em si e o consumidor por equiparação ou bystander. O conceito de consumidor é, no entendimento de Newton de Lucca, um conceito plurívoco e plurívoco analógico, isso porque apresenta um conceito fundamental expresso pelo art. $2^{\circ}$ e conceitos por equiparação fundados sob o princípio da prevenção do dano (LUCCA, 2008).

O conceito de consumidor de per si, conforme dito, é descrito no art. $2^{\circ}$ desse Código que estabelece que o consumidor é aquele que adquire produto ou serviço como destinatário final.

Nesse sentido, Bellini Jr. (2006, p. 64-65) expressa que destinatário final:

(...) é aquele que adquire certo bem ou serviço para seu uso, não tendo a pretensão de utilizá-lo como bem de produção. Quanto à pessoa física se compra um bem para utilizá-lo como consumidor final, o enunciado legal acima transcrito se aplica de imediato: ela é consumidora. Entretanto, no que tange à pessoa jurídica, é preciso fazer a ressalva que somente será consumidora se o bem adquirido não servir como insumo ou meio para a sua produção que será colocada no mercado novamente.

Entretanto, a conceituação do consumidor pelo uso da expressão destinatário final, além da expressa menção da pessoa jurídica como consumidora deu ensejo a duas diferentes teses acerca do âmbito de aplicação do CDC. De um lado há os autores da corrente finalista que expressam que se deve interpretar o termo "destinatário final" de forma restrita, englobando apenas aqueles que se valem do produto para fins domésticos (CABRAL, 2008), ou seja, o destinatário fático e econômico do produto (BENJAMIN, MARQUES, BESSA,

2010). Dessa forma, não estaria no âmbito de aplicação do Direito do Consumidor a relação entre dois empresários mesmo que o produto não seja usado para fins de comercialização. Além do mais, para os finalistas a subordinação econômica é essencial ao conceito de consumidor, não sendo consumidor aquele que não se apresenta vulnerável ou que não seja hipossuficiente economicamente (MIRAGEM, 2002).

A tese maximalista, por sua vez, afirma que todo o mercado de consumo está sob a estruturação legal do CDC e, dessa forma, a destinação do produto deixa de ser relevante, bastando a destinação fática do mesmo (BENJAMIN, MARQUES, BESSA, 2010), podendo 
abranger, desde que destinatários finais, mesmo empresários ou empresas na proteção oferecida pelo Código de Defesa do Consumidor (CABRAL, 2008).

Tendo em vista essas questões, o STJ adota uma posição mitigada, chamada por Cabral de posição finalista-subjetiva, e por Cláudia Lima Marques de finalismo aprofundado, em que a vulnerabilidade da pessoa jurídica consumidora não é presumida, mas sim verificada caso a caso, e apenas assim ensejando ou não a aplicação do CDC. Dessa forma, para que seja possível a caracterização da pessoa jurídica como vulnerável há a necessidade de produção de provas nesse sentido (CABRAL, 2008).

Vale lembrar que a finalidade do CDC deve sempre ser um norte para a sua aplicação e, dessa forma, não se pode esquecer o princípio da igualdade real e de que o intuito da criação desse diploma legal foi restabelecer o equilíbrio entre as partes da relação jurídica de consumo. Desse modo, se houver necessidade de reequilíbrio das partes, por questões de vulnerabilidade de uma frente à outra, estar-se- á diante de uma relação de consumo (sem se esquecer do pressuposto de ser destinatário final). ${ }^{22}$ Entretanto, se as duas estiverem em pé de igualdade tanto jurídica, quanto técnica, quanto econômica, entre outras, ou seja, se tiverem paridade de condições, não há que se falar de aplicação do CDC para a pessoa jurídica. Essa diferenciação, entretanto, não ocorre no caso de consumidor pessoa física que sempre será considerado vulnerável. ${ }^{23}$

Já o conceito de consumidor por equiparação ou bystander está previsto nos arts. 17, 29 e $2^{\circ}, \S$ único. Por esses artigos, podem-se inferir três tipos de consumidores por equiparação: o consumidor como ente coletivo, aqueles que sofrem com as práticas comerciais e as vítimas de eventos danosos ocorridos em decorrência da relação de consumo potencial. Esses conceitos de consumidor visam à efetivação da tutela do consumidor, prevendo que, mesmo fora da relação jurídica de consumo strictu sensu, ou seja, levando-se em consideração apenas o destinatário final do produto ou serviço, há pessoas que podem ser prejudicadas pelas atividades dos fornecedores (BENJAMIN, MARQUES, BESSA, 2010).

O conceito de fornecedor, diferentemente do conceito de consumidor, é mais simples e enseja menos divergências. Para Newton de Lucca (2008), o conceito de fornecedor precisa estar apoiado na questão da atividade, tendo em vista a habitualidade e o profissionalismo.

\footnotetext{
${ }^{22}$ Em sentido contrário entende Zapater: "Não nos parece que o Código se destina a proteger qualquer relação em que haja vulnerabilidade, e mesmo tal comprovação, especialmente no caso da pessoa jurídica, parece ser árdua.” (ZAPATER, 2001, p.181).

${ }^{23}$ Em outro sentido, reafirma Zapater a importância do conceito de consumidor estar adequado aos ditames constitucionais previstas a respeito da ordem econômica e social. Desse modo, o conceito de consumidor só seria constitucional se levasse em consideração o princípio da soberania nacional, da livre iniciativa entre outros previstos no art.170 da CF. Nessa seara estaria descrito ainda o princípio de tratamento favorecido para empresas de pequeno porte ou microempresas de tal monta que frente a determinada empresa de grande porte pode vir a ser considerada consumidora tendo em vista a higidez do mercado e a segurança do ciclo econômico de repasse de mercadorias até o consumidor final pessoa física. (ZAPATER, 2001, pp.190-191).
} 
Não pode ser considerado fornecedor o sujeito que não tem habitualidade na prestação do serviço ou fornecimento de produtos, sendo essencial a questão da empresarialidade, que engloba ainda tanto a atividade, e não o mero ato (que estaria sujeito à aplicação do Direito Civil), quanto o profissionalismo.

O objeto da relação jurídica de consumo, por sua vez, são os serviços e os produtos definidos no art. $3^{\circ}, \S \S 1^{\circ}$ e $2^{\circ}$ do Código de Defesa do Consumidor.

Desse modo, a partir da análise sucinta dos elementos de uma relação de consumo, pode-se conceituar essa como sendo o liame jurídico entre fornecedor e consumidor tendo em vista um produto ou serviço do mercado de consumo. A relevância do tema é a determinação do âmbito de aplicação do CDC, tendo em vista, no presente trabalho, a caracterização do caso Mariana como enquadrado nas normas de consumo ou não.

Conforme previamente relatado, o caso Mariana envolveu a Mineradora Samarco, concessionária de serviço público ${ }^{24}$, conforme artigo 176 da Constituição Federal ${ }^{25}$ em que houve o rompimento de suas barragens e o consequente despejo de rejeitos da produção de minério de ferro, obrigando muitas pessoas a abandonarem suas casas e causando até mesmo a morte de algumas outras.

Como concessionária de serviço público, à Empresa Samarco aplica-se o conceito de fornecedor (artigo $3^{\circ}$, caput, do CDC)? De acordo com o artigo $6^{\circ}, \mathrm{X}$, do CDC, é um direito dos consumidores a adequada e eficaz prestação de serviços públicos. Pelo artigo 22, caput e parágrafo único, as concessionárias ou permissionárias de serviços públicos são obrigadas a fornecer serviço adequado, eficiente e mesmo seguro. Além do mais impõe o dever de reparação dos danos no caso de descumprimento dessa regra. Assim, parece claro que uma concessionária de serviços públicos submete-se ao âmbito de aplicação do CDC ao caso de eventos danosos conforme o princípio da proteção já citado. E ainda de acordo com o artigo 17 do CDC toda vítima do evento de consumo é considerado consumidor por equiparação para fins de responsabilidade civil.

Assim, de acordo com a doutrina a respeito da relação jurídica de consumo parece clara a possibilidade de aplicação do CDC ao desastre ecológico ocorrido de Mariana/MG.

\footnotetext{
${ }^{24}$ Por serviço público entende Helly Lopes Meirelles (1997, p. 296): “Serviço público é todo aquele prestado pela Administração ou seus delegados, sob normas e controles estatais para satisfazer necessidades essenciais ou secundárias da coletividade, ou simples conveniências do Estado".

${ }_{25}$ Art. 176. As jazidas, em lavra ou não, e demais recursos minerais e os potenciais de energia hidráulica constituem propriedade distinta da do solo, para efeito de exploração ou aproveitamento, e pertencem à União, garantida ao concessionário a propriedade do produ to da lavra. (BRASIL, Constituição Federal (1988). Disponível em: 〈http://www.planalto.gov.br/ccivil_03/Constituicao/Constituicao.htm> Acesso em: 29.03.2016.
} 


\section{MEDIAÇÃO, CÓdIGO DE DEFESA DO CONSUMIDOR E CASO MARIANA}

Em um primeiro momento, apesar de inserido no âmbito de aplicação do Código de Defesa do consumidor, é possível a utilização da ferramenta da mediação para compor os interesses presentes no conflito entre Estado, concessionária de serviço público e vítimas de evento danoso de consumo como no caso Mariana. Dessa forma prevê o artigo $1^{\circ}$ da Lei de Mediação ao dispor a possibilidade de mediação entre particulares e entre particular e Administração Pública. ${ }^{26} \mathrm{E}$ ainda o artigo $3^{\circ}$ ao prever a possibilidade de mediação sobre direitos indisponíveis que aceitam transação.

Entretanto, além dos limites impostos a uma mediação, tais quais, a transacionalidade do direito indisponível, a prioridade sobre direitos disponíveis, a participação ativa das partes do conflito, o monitoramento das posições, a voluntariedade da participação. No caso de uma mediação em que concebe direitos previstos no CDC e, portanto, direitos com caráter de ordem pública, porém transacionáveis por serem direitos patrimoniais indenizáveis, há ainda a necessidade de homologação via judicial e exigência de oitiva do Ministério Público, conforme a previsão legal do artigo $3^{\circ}$, §2º da Lei 13.140/2015.

Além do mais, tendo em vista a necessidade de revisão por parte do Ministério Público como custos legis, há também necessidade - que coaduna inclusive com a proposta de mediação alcançar maior representatividade possível para tornar composição um processo nãoadversarial, amigável, de escuta ativa - de representação das partes atingidas por um outro órgão como a Defensoria Pública, se for o caso, ou mesmo por representantes coletivos e particulares das vítimas, sendo dispensada a representação nos ditames da Lei. ${ }^{27}$

Nesse sentido, os elementos do desenho de sistemas de resolução de disputas tal como descrito por Nádia de Araújo e Olivia Früst (2014) para o caso do voo 447 pode ser comparado em relação aos direitos do consumidor e as suas respectivas indenizações. Para que isso ocorra ao caso Mariana é preciso superar o tradicional modo de pensar o Direito e construir estruturas que permitam a Mediação tal como nova forma de pensar o Direito. Para isso, poderíamos começar por atender ao princípio de transparência, dotando os membros

\footnotetext{
${ }^{26}$ Art. $1^{\circ}$ Esta Lei dispõe sobre a mediação como meio de solução de controvérsias entre particulares e sobre a autocomposição de conflitos no âmbito da administração pública. (BRASIL, Lei 13.140/2015. Dispõe sobre a mediação entre particulares como meio de solução de controvérsias e sobre a autocomposição de conflitos no âmbito da administração pública; altera a Lei no 9.469 , de 10 de julho de 1997 , e o Decreto no 70.235, de 6 de março de 1972; e revoga o § 2o do art. 6o da Lei no 9.469, de 10 de julho de 1997. Disponível em: < http://www.planalto.gov.br/ccivil_03/_Ato2015-2018/2015/Lei/L13140.htm> Acesso em: 29.03.2016).

${ }_{27}$ Art. 10. As partes poderão ser assistidas por advogados ou defensores públicos.

Parágrafo único. Comparecendo uma das partes acompanhada de advogado ou defensor público, o mediador suspenderá o procedimento, até que todas estejam devidamente assistidas. (BRASIL, Lei 13.140/2015. Dispõe sobre a mediação entre particulares como meio de solução de controvérsias e sobre a autocomposição de conflitos no âmbito da administração pública; altera a Lei no 9.469 , de 10 de julho de 1997 , e o Decreto no 70.235, de 6 de março de 1972; e revoga o § 2o do art. 6 o da Lei no 9.469, de 10 de julho de 1997 . Disponível em: < http://www.planalto.gov.br/ccivil_03/_Ato2015-2018/2015/Lei/L13140.htm> Acesso em: 29.03.2016).
} 
afetados e seus representantes de conhecimento sobre os compromissos firmados, que, como visto nas reportagens supracitadas ainda carecem de informação.

Para atender ao quesito da isonomia é preciso que haja um mediador neutro que não o próprio poder público interessado, o principio da confidencialidade estará restaurado com o compromisso do mediador neutro em dar fim aos textos produzidos, estratégias, resumos após o final do procedimento e a eficiência assentada na chamada dos representantes, tanto defensoria quanto ministério público, em como outros representantes para de forma célere resolver o conflito.

\section{Conclusões}

1. A mediação deve ser vista como uma nova forma de pensar o Direito, em que se trasnforma o pensamento adversarial, assentado no conflito e na contra-argumentação, para a ideia de composição não-adversarial, amigável, assentado na comunicação e na escuta ativa dos interesses presentes e na solução não só do atual conflito como possíveis desentendimentos futuros.

2. O instrumento da mediação também é um modo de empoderar as pessoas e lhes devolver a capacidade de resolver seus próprios problemas, sem ter que recorrer ao Poder Judiciário, sendo assim, uma forma de melhorar a cidadania, bem como o acesso à Justiça célere.

3. A composição do conflito por meio da mediação traz a sensação de resolução da lide de uma forma em que ambas as partes ganham, retirando o aspecto ganha-perde do processo judicial.

4. A mediação é recomendável, para além de direitos disponíveis, para direitos indisponíveis passíveis de transação como são os direitos do consumidor, conforme previsto pelo artigo $1^{\circ}$ do $\mathrm{CDC} .^{28}$

5. É possível a mediação no âmbito da Administração Pública, coadunando-se com os princípios elencados no artigo 37, caput, da Constituição Federal $^{29}$.

6. Uma das vantagens do uso da mediação para a resolução de casos que envolvam muitas partes e, portanto, muitos interesses distintos, é que ela permite o monitoramento desses interesses para alcançar uma postura de cooperação entre as partes, sociedade e poder

\footnotetext{
28 Art. $1^{\circ} \mathrm{O}$ presente código estabelece normas de proteção e defesa do consumidor, de ordem pública e interesse social, nos termos dos arts. $5^{\circ}$, inciso XXXII, 170, inciso V, da Constituição Federal e art. 48 de suas Disposições Transitórias. (BRASIL, Código de Defesa do Consumidor (1990). Disponível em: < http://www.planalto.gov.br/ccivil_03/leis/L8078.htm> Acesso em: 29.03.2016.)

${ }^{29}$ Art. 37. A administração pública direta e indireta de qualquer dos Poderes da União, dos Estados, do Distrito Federal e dos Municípios obedecerá aos princípios de legalidade, impessoalidade, moralidade, publicidade e eficiência e, também, ao seguinte: (BRASIL, Constituição Federal (1988). Disponível em: < http://www.planalto.gov.br/ccivil_03/Constituicao/Constituicao.htm> Acesso em: 29.03.2016.
} 
público, e só assim resolver e evitar conflitos. Para que isso aconteça há necessidade de envolver todas as partes no procedimento de mediação.

8. O caso Mariana guarda semelhança, no tocante aos direitos do consumidor, com o desastre da Air France - voo 447, podendo se valer de um modelo similar de programa de indenização baseado em solução extrajudicial com apoio de diversas instituições do Poder Público, empresas, e cidadãos envolvidos diretamente com o caso e seus representantes.

9. Os princípios de transparência, autonomia da vontade, confidencialidade, eficiência e isonomia sistema de resoluções de disputas do voo 447 servem também de início como valores a serem perseguidos na resolução do Caso Mariana, assim com a sua estrutura podem servir de modelo no que tange ao aspecto das indenizações, sem prejuízo de alterações nos valores já que se tratam de perdas distintas.

10. Ao caso Mariana aplicam-se as normas de proteção do consumidor por ser considerado consumidor por equiparação como vítima de evento danoso de consumo (art. 17 do CDC) e ainda pela Samarco ser tida como fornecedora por ser empresa concessionária de serviço público (art. 22 do CDC).

11. O Código de Defesa do Consumidor prevê diversos dispositivos que asseguram a sua aplicação em caso de serviços públicos, em especial, naqueles em que a segurança do consumidor é afetada.

12. Dentre os limites apresentados pela mediação que envolve consumidores e concessionária de serviços públicos estão: a necessidade de homologação pelo Judiciário e a oitiva do Ministério Público, sempre garantindo a isonomia no procedimento, a boa-fé e a autonomia da vontade das partes, buscando o consenso entre elas para a composição do conflito.

\section{REFERÊNCIAS}

AlmEIDA, João Batista de. A proteção jurídica do consumidor. 3.ed. São Paulo: Saraiva, 2002.

AlmeIDA, Tânia. Caixa de Ferramentas em Mediação: Aportes práticos e teóricos. São Paulo: Dash, $1^{\text {a }}$ edição março, 2014.

ARAÚJO, Nádia de; Furst, Olívia. Um exemplo brasileiro do uso de Mediação em eventos de grande impacto: o programa de indenização do voo 447. Revista de Direito do Consumidor, v. 91, p.337-349, jan./fev., 2014. 
Bellini JR., Antonio Carlos. A inversão do ônus da prova no Código de Defesa do consumidor. São Paulo: Servanda Editora, 2006.

BenJamin, Antônio Herman V.; MARQues, Cláudia Lima; Bessa, Leonardo Roscoe. Manual de direito do consumidor. 3. ed., São Paulo: RT, 2010.

CABRAL, Érico de Pina. Inversão do ônus da prova no processo civil do consumidor. São Paulo: Método, 2008.

Cunha, J.R. \& Noronha, R. Mediação de Conflitos Comunitários e Facilitação de Diálogos: Relato de uma experiência na Maré. Rio de Janeiro: Escola de Direito da FGV, 2010.

FERRAZ JR., Tércio Sampaio. Introdução ao estudo do Direito: técnica, decisão, dominação. 5.ed. São Paulo: Atlas, 2007.

Grinover, Ada Pellegrini; SAdeKe, Maria Tereza; Watanabe, Kazuo. Diálogos sobre Justiça: Estudo qualitativo sobre boas práticas em mediação no Brasil. Brasília: Ministério da Justiça, Secretaria de Reforma do Judiciário, 2014.

Kelsen, Hans. Teoria Pura do Direito. Traduzido por João Baptista Machado. 3.ed. São Paulo: Martins Fontes, 1991.

LuCCA, Newton de. Direito do Consumidor: Teoria Geral da Relação Jurídica de Consumo. 2.ed. São Paulo: Quartier Latin, 2008.

Marconi, Marina de Andrade; LAKATos, Eva Maria. Fundamentos de Metodologia Científica. 6.ed. São Paulo: Atlas, 2007.

MeIRELLES, Helly Lopes. Direito Administrativo Brasileiro. 22.ed. São Paulo: RT, 1997.

Miragem, Bruno Nubens Barbosa. O direito do consumidor como direito fundamental: conseqüências jurídicas de um conceito. Revista de Direito do Consumidor, São Paulo, n.43, p.111-132, jul./set., 2002.

Muniz, J. de Paiva et al. Arbitragem e Mediação: Temas Controvertidos. Rio de Janeiro: Editora Forense, 2014. 
NADER, Paulo. Introdução ao Estudo do Direito. 30.ed. Rio de Janeiro: Forense, 2008.

Venosa, Sílvio de Salvo. Introdução ao Estudo do direito. 2.ed. São Paulo: Atlas, 2008.

ZAPATER, Tiago Cardoso. A interpretação constitucional do Código de defesa do Consumidor e a pessoa jurídica como consumidor. Revista de Direito do Consumidor, São Paulo, n. 40, p.170-198, out./dez. 2001. 